\title{
UNA ATALAYA PARA EL SIGLO XX
}

JESÜS GÓMEZ SERRANO

Departamento de Historia /UAA

Alfonso Pérez Romo, Testimonio de unos días, Universidad Autónoma de Aguascalientes/Instituto Cultural de Aguascalientes, Aguascalientes, 1999.

1 ice un viejo proverbio árabe, citado por Marc Bloch en su Apología de la historia, que los hombres se parecen más a su época que a sus padres. La idea puede resultar de pronto extraña, sobre todo si se repara en la forma obvia en la que los ojos, la complexión física, el tono de la voz o hasta la manera de caminar de alguien recuerdan no un paisaje o un acontecimiento histórico, sino precisamente ciertos rasgos físicos de los progenitores.

1 Texto leído con motivo de la presentación del libro de A. Pérez Romo, el 3 de diciembre de 1999, en el auditorio Ignacio T. Chávez de la UAA.
Las cosas se nos pueden aclarar si fijamos nuestra atención en la tesitura moral de las personas. El libro del doctor Alfonso Pérez Romo es una demostración de la profunda verdad que asiste a ese dicho. La organización misma del libro y los temas en los que se detienen la mirada y el corazón del autor hablan con claridad de las preocupaciones que han marcado las últimas décadas.

Los textos reunidos en el primer capítulo del libro constituyen un buen retrato de la forma en la que la ciudad de Aguascalientes ha vivido los retos e inconvenientes que de manera inevitable trae aparejados eso que hemos dado en llamar "progreso". Sin duda, las suyas son opiniones vertidas a título individual, pero es evidente que se trata de preocupaciones compartidas y muy propias de la época. El doctor Pérez Romo es un ena-. 
morado de la ciudad; de su villa, como nostálgica y cariñosamente la llama. Como buen enamorado, a ratos idealiza las cualidades de su dama y la imagina más bella y mejor compuesta de lo que en realidad es. Pero el suyo es un amor inteligente y preocupado, que le permite advertir que el progreso tiene sus inconvenientes, que hay rincones y rasgos de carácter que lastimosamente se han perdido, que el afán de renovación a veces supone la ociosa y costosa destrucción de monumentos importantes y que el futuro no es todo lo sonriente que sería deseable.

Esta misma idea aparece plasmada en el texto de contraportada del libro; ahí se habla, sin ocultar el dolor y la nostalgia, de la muerte silenciosa del "viejo Aguascalientes", que es el del autor, el que lo vio crecer, al que aprendió a amar. Al mismo tiempo, se habla de "ansiedad" ante la emergencia del nuevo Aguascalientes, el que está rompiendo "el cascarón de la historia”. Quiero interpretar esa ansiedad como la angustia vigilante de un padre bondadoso que ve con orgullo las pequeñas hazañas, el desenfado y las travesuras de su vástago, sin que se le oculte, al mismo tiempo, que el parto de lo nuevo tiene siempre su costo y sus riesgos.
Al lado de su amor por el terruño, o tal vez inextricablemente confundido con él, aparecen su devoción y su entrega a la causa de la educación. Más que las observaciones de detalle sobre el desarrollo de la Universidad Autónoma de Aguascalientes, la creación de la Escuela de Medicina y el futuro de la educación superior, llama la atención la fidelidad del doctor Pérez Romo al tema educativo.

La generosidad del doctor Pérez Romo es claramente perceptible en muchos de sus escritos. Al comentar un libro del historiador valenciano Vicente Ribes Iborra, al recordar a su admirado colega, el doctor David Reynoso Jiménez, al presentar un poemario de Rosa Luz de Luna o al introducir una exposición de la pintora Alicia Miner, Pérez Romo encuentra la forma de subrayar los méritos. Seguramente advirtió límites y defectos en esos libros que leyó, en esos personajes a los que conoció de cerca y en esas obras en las que posó su mirada crítica, pero él prefirió siempre, menos por simple cortesía que por esa generosidad caballeresca que en forma inevitable lo traiciona, subrayar lo bueno y meritorio. Sinceramente, no creo que se trate de elecciones hechas por conveniencia o comodidad, sino de manifestacio- 
nes de uno de los rasgos más acusados de su carácter.

Hijo de su tiempo y marcado por su cultura hispánica, el doctor Pérez Romo dedica un capítulo entero a la llamada fiesta brava, a la que él se empeña en defender como auténtico arte. Lo evidente es que no se trata para él de un pasatiempo o una simple diversión, sino de un rasgo profundo de esa cultura a la que ha aprendido a conocer y a apreciar. Entre los aficionados a esa fiesta se distinguen claramente los pocos que son capaces de justipreciar lo que pasa en el ruedo de la multitud ignorante que llena las plazas. Sin lugar a dudas, el doctor Pérez Romo pertenece a los primeros. Como a todos los verdaderos aficionados, lo enojan las marrullerías de los empresarios, la falta de convicción de algunos diestros, que obtienen trofeos a base de concesiones, y la insolente algarabía de ese "público de feriantes" que llena los tendidos pero no es capaz de aquilatar una auténtica faena. Sin embargo, todo eso y más es capaz de sufrirlo y perdonarlo un auténtico aficionado cuando asiste al milagro de "una lección taurina" ofrecida por Roberto Domínguez o a una prodigiosa faena de Armillita.
El libro del doctor Pérez Romo nos invita a mirar atrás y a ponderar algunas de las dimensiones de este siglo que está por terminar. La invitación resulta un tanto extraña, pues se ha apoderado de los medios masivos de comunicación, de los fabricantes de automóviles, de las revistas literarias y hasta de los congresos científicos algo que podemos llamar "la fiebre del tercer milenio", cuyo arribo, por cierto, se saludó con anticipado interés. Vale la pena recordar, a este respecto, lo que alguna vez escribió Leonardo da Vinci: "Cuando el hombre espera con feliz impaciencia el nuevo día, la nueva primavera, el año nuevo (y podríamos agregar: el nuevo milenio) no comprende que de este modo aspira a su propia muerte".

La invitación del doctor Pérez Romo va en un sentido completamente diferente. Él nos invita a pensar en el siglo XX, que es y ha sido el suyo; en las guerras y conflictos que ha vivido con dolor y preocupación; en la ciudad que ha visto crecer y sufrir a veces los embates del deterioro y la deshumanización; en la todavía muy joven Universidad que él y otros soñaron y que tuvo la fortuna de dirigir; en los hombres con los que ha 
convivido y cuyas virtudes celebra en forma alegre y abierta; en los libros que ha leído y comentado; en todo eso que ha convertido en las pasiones de su vida, como las artes plásticas y la fiesta de los toros.

Su afán de ver hacia atrás, aprendiendo del pasado, y su callado escepticismo ante muchas de las sorpresas que nos deparan la globalización, la cibernética y el nuevo milenio, son evidentes en la arquitectura misma del libro y en los temas, personas, ciudades y problemas en los que se fija la atención. Orgulloso de su sangre española, de su idioma y de su historia, el doctor Pérez Romo comparte con sus lectores su asombro ante el paisaje ibérico, la profunda impresión que le causan las ruinas de Machu Picchu, la fascinación ante las grandes capitales sudamericanas. El artículo que dedica a Cuba y a lo que él llama su "revolución sin fruto" es interesante, pues muchos de los cuestionamientos que hizo hace diez o quince años, que fueron en su momento identificados como manifestaciones de una actitud contraria al cambio social, son ahora compartidos por toda la izquierda democrática.

A veces los libros son interesantes no sólo por lo que dicen, sino tam- bién por lo que no dicen. A mí me intriga la concentrada atención que presta el autor a lo hispánico y su silente indiferencia ante casi todo lo anglosajón. No es casual, por ejemplo, que el único artículo dedicado a California no se refiera a los modernos parques industriales, a la asombrosa economía de ese pujante estado de la Unión Americana, al buen vino que se produce en los valles de Napa y Sonoma o a las hamburguesas, sino precisamente a las misiones fundadas en la época colonial por los españoles.

Sin proponérselo, acaso sin darse cuenta, a sus setenta y cinco años, el doctor Pérez Romo se convierte en un contestatario; un hombre que no se suma al regocijo ingenuo que provoca el muy mentado advenimiento del nuevo milenio, sino que prefiere volver la vista atrás y pasar revista a su vida, su siglo, sus pasiones y sus amigos.

$$
\text { *** * }
$$

Aunque no se trata de un libro de memorias, el libro del doctor Pérez Romo constituye un interesante testimonio de la travesía de un hombre. De manera inevitable, a lo largo de setenta y cinco años de vida 
provechosa y atenta, el autor de este libro ha ido fijando mojoneras, señales y encrucijadas. Ahora recoge todo eso y lo que nos da a leer, en cierta forma, es su "geografía sentimental", un mapa que nos ayuda a seguirlo en sus viajes, sus lecturas, sus amistades y sus pasiones. Creo que cuando el Dr. Pérez Romo dice que no es un escritor ni quiere parecerlo, lo que nos está diciendo en realidad es que se siente un hombre como cualquier otro; no un prócer de la cultura ni un maestro de las nuevas generaciones, sino un ser humano empeñado apenas en descifrar el misterio de su propia e intransferible existencia. Pienso que ésta es la secreta razón por la que la lectura de este libro resulta interesante: su autor es un hombre como cualquiera de nosotros, que comparte con cierta timidez sus experiencias. Sin la insufrible pedantería de quienes se sienten superdotados, sin querer darle a nadie lecciones de nada, don Alfonso nos entrega un retrato personal y a ratos hasta íntimo, en algunos de cuyos rasgos de pronto creemos identificarnos. La sinceridad y la modestia de este empeño, lejos de volverlo ocioso, le dan todo su crédito $\mathrm{y}$ valor.
$* * *$

Desde que empecé a tratarlo, siendo él rector de la UAA y yo miembro de la primera generación de estudiantes de sociología (1976-1981), me cautivaron su generosidad personal, su genuina preocupación por la educación y su inquebrantable convicción de que era posible y hasta necesario discutir las ideas. Siendo él responsable de la marcha de la institución y formando algunos de nosotros un grupo de alumnos inquietos, alaraquientos y hasta un poco revoltosos, era inevitable que se presentaran las dificultades. Como al doctor le había tocado la época de la Guerra Fría y nosotros leíamos a Marx y simpatizábamos con el partido político que estaba formando Heberto Casti1lo, se concluyó en forma fácil que éramos una especie de encarnación, a nivel local, de la muy peligrosa "amenaza comunista". Él era muy sincero en esa convicción y nosotros muy irreductibles en lo tocante a nuestras ideas. En aquellos días, lejanos en el tiempo pero no en la memoria y el afecto, hubo de todo: una revista en la que magnificábamos y caricaturizábamos los excesos de nuestras autoridades, conciertos de música latinoamericana, reuniones 
"clandestinas" en las que planeábamos la revolución y hasta una marcha en la que, con más ruido que argumentos, protestamos contra el aumento de las colegiaturas.

Lo que quiero recordar es que, a pesar de todas las diferencias y de la forma casi abierta en la que llegamos a enfrentarnos, el doctor nunca nos cerró las puertas de la rectoría. Seguramente no compartía nuestras ideas y censuraba el ímpetu con el que a veces las defendíamos, pero nunca dejó de recibirnos y de vernos con algo que a la distancia, no sé si en forma certera, identifico como paternal benevolencia. No estaba de acuerdo con nosotros, pero creía que debía apostarle al ímpetu y el deseo de cambio que veía en esos jóvenes. En algún momento, cuando las cosas se habían puesto realmente difíciles, le pedimos cierto apoyo económico para nuestra revista, la misma en la que lo criticábamos. Sin pensarlo dos veces, nos dio el dinero que le pedíamos, el cual tomó, no de las arcas universitarias, lo que para él, como rector, hubiera sido muy fácil, sino de su propia cartera. Ese día nos dio, sin saberlo ni proponérselo, una imborrable lección de generosidad e integridad. *te * *

Es un acto de elemental justicia el que los artículos y ensayos de este hombre aparezcan publicados bajo el sello de dos instituciones consagradas a la educación y la promoción de la cultura. El doctor Pérez Romo fue rector de la UAA en el periodo 1978 1981 y director del Instituto Cultural de Aguascalientes entre 1985 y 1986. En la UAA aceptó el desafío de consolidar la obra iniciada por D. Humberto Martínez de León, rector fundador de nuestra casa de estudios, y en el ICA encabezó los esfuerzos tendientes a transformar la antigua Casa de la Cultura en Instituto. El que ambas instituciones sumen ahora fuerzas para publicar este libro supone un merecido, abierto e inteligente reconocimiento a la labor hecha en su momento por el Dr. Pérez Romo.

Por boca del Quijote, Cervantes decía que entre las virtudes que por fuerza debían adornar a los buenos caballeros y a quienes ejercen la autoridad, una de las primeras era la del agradecimiento; a Sancho Panza, convertido en gobernador de la ínsula Barataria, don Quijote lo prevenía contra la ingratitud, a la que llama "hija de la soberbia y uno de los mayores pecados que se sabe". Pienso 
que en este caso hablamos de una virtud que es también esencial para las instituciones. Con cuánta frecuencia hemos atestiguado la forma poco noble en la que las instituciones se vuelven en contra de sus hijos o de sus creadores. La pequeñez, el resentimiento y la amargura que con triste frecuencia manchan a los hombres, anidan también en las instituciones de educación y cultura.

Creo que la Universidad Autónoma de Aguascalientes y el Instituto Cultural han acertado al patrocinar conjuntamente la edición de esta colección de artículos, reseñas y apuntes del doctor Alfonso Pérez Romo. Cuando surgió la idea de reunir en un libro todos esos materiales, el más escéptico y reticente de todos era él mismo: pensaba que lo suyo eran escritos de ocasión, carentes de unidad temática y de aliento. A mí me parece claro que el libro está bien logrado y que el aliento lo da con largueza la curiosidad polifacética del autor y su capacidad para convertir un tema cualquiera en una legítima preocupación del espíritu. Su mirada inteligente y generosa, puesta en una época que es la nuestra, en pasiones que compartimos y en problemas que definitivamente no hemos resuelto, nos recuerda algunas de las tareas que te- nemos por delante y lo mucho que podemos aprender del pasado inmediato.

$$
* * *
$$

Voy a hacer un último comentario sobre algo que en el libro no aparece en forma explícita, pero que de alguna manera impregna todos los artículos y ensayos reunidos. Durante los úl timos diez o quince años hemos ido aprendiendo en México que, pese a todos sus inconvenientes, la democracia es la menos mala de las formas de gobierno. Al país le ha costado un trabajo enorme reedificar su vida política sobre esos nuevos cimientos. Pero no sólo la política se ha democratizado: también lo han hecho, en mayor o menor medida, otros muchos ámbitos de la vida pública. De alguna manera, tendemos ahora a medir con el rasero de la democracia y el igualitarismo los afanes de las instituciones y de las personas, lo cual en sí no es malo, aunque no deja de tener serios inconvenientes y de prohijar grandes injusticias.

Al respecto, el novelista español Javier Marías recordaba recientemente que el noble ideal democrático está expuesto a tergiversaciones e injustas manifestaciones de todo tipo. Se 
nos ha olvidado, decía, que "los hechos de los hombres no son iguales, no valen lo mismo, no son equiparables"; hay cierto fanatismo igualitarista que sostiene, por ejemplo, que "toda creación artística es valiosa y que ninguna tiene por qué ser mejor o peor que ninguna otra", o que toda opinión es en sí misma importante, sin reparar en su pertinencia o sus méritos intrínsecos. Podemos acordar que todos los hombres son, en principio, iguales, pero no hay que olvidar que cada persona es en muy buena medida responsable de la forma en la que va tejiendo su propia historia.

El libro del doctor Pérez Romo es el testimonio de alguien que ha ca- minado por la vida con los ojos y el corazón abiertos. En cierta forma, lo singularizan menos los libros que ha leído, los viajes que ha hecho y las oportunidades que le ha regalado la vida, que su voluntad de convertir todo eso en experiencia vital. Don Alfonso es uno de esos hombres para quienes la vida es un misterio, un don y un desafío. En su libro trata de entender ese misterio, agradece ese don y asume como antiguo caballero castellano ese desafío. En la medida en la que se puede aprender de la experiencia ajena, su libro nos ayuda a trazar y descifrar nuestro propio itinerario vital. 